\title{
Cardiopulmonary bypass in malignant hyperthermia susceptible patients: A systematic review of published cases
}

\author{
Thomas Metterlein, MD, ${ }^{\mathrm{a}}$ Wolfgang Zink, MD, ${ }^{\mathrm{a}}$ Eva Kranke, RN, ${ }^{\mathrm{c}}$ Assad Haneya, MD, \\ Bernhard Graf, MSc, MD, ${ }^{\mathrm{a}}$ and Peter Kranke, $\mathrm{MD}^{\mathrm{d}}$
}

\begin{abstract}
Objectives: Malignant hyperthermia susceptibility is an important risk factor during general anesthesia. Affected patients have an asymptomatic but potentially lethal hypermetabolic reaction after contact with volatile anesthetics or succinylcholine. Classic symptoms include hemodynamic instability, combined with acidosis, rigor, and hyperthermia. During cardiopulmonary bypass, these signs may be obscured, delaying correct diagnosis and lifesaving treatment. Malignant hyperthermia-susceptible individuals are more sensitive to heat and stress, so rewarming and catecholamine administration may trigger an episode, necessitating prophylactic measures.
\end{abstract}

\begin{abstract}
Methods: This systematic review identified typical malignant hyperthermia symptoms during cardiopulmonary bypass and investigated other factors in cardiac surgery that might trigger an episode in susceptible individuals. Approaches used to treat and prevent malignant hyperthermia during cardiopulmonary bypass were systematically analyzed. We conducted a systematic search for reports about malignant hyperthermia and cardiopulmonary bypass. Search terms included malignant hyperthermia and cardiopulmonary bypass, extracorporeal circulation, or cardiac surgery.

Results: We found 24 case reports and case series including details of 26 patients. In 14 cases, malignant hyperthermia crises during or shortly after cardiopulmonary bypass were described. Fourteen reports discussed prevention of an episode. Early symptoms of a malignant hyperthermia episode include excessive carbon dioxide production and metabolic acidosis. Massively increased creatine kinase levels are a strong indicator of a malignant hyperthermia reaction. Rewarming is associated with development of clinical signs of malignant hyperthermia.
\end{abstract}

Conclusions: In potentially susceptible patients, apart from avoiding classic trigger substances, aggressive rewarming should not be applied. Hemodynamic instability in conjunction with the described symptoms should result in a diagnostic algorithm. (J Thorac Cardiovasc Surg 2011;141:1488-95)

Malignant hyperthermia (MH) remains an important risk factor during general anesthesia. In initially symptom-free patients, a potentially lethal hypermetabolic syndrome can develop after contact with so-called trigger substances, namely volatile anesthetics (halothane, enflurane, isoflurane, sevoflurane, and desflurane) and succinylcholine (INN suxamethonium). ${ }^{1-5}$ The overall incidence of $\mathrm{MH}$ is uncertain, but it is estimated to be between 0.5 to 2 in 100,000 general anesthesia procedures. ${ }^{6-9}$ The prevalence of MH susceptibility could be as high as 1 in 3.000 in the general population. ${ }^{10}$ Because of the widespread use of volatile anesthetics in cardiac surgery, with or without cardiopulmonary bypass (CPB), $\mathrm{MH}$ remains a relevant concern.

From the Departments of Anesthesiology ${ }^{\mathrm{a}}$ and Cardiosurgery, ${ }^{\mathrm{b}}$ University Hospital Regensburg, Regensburg, Germany; and the Departments of Cardiosurgery ${ }^{c}$ and Anesthesia and Critical Care, ${ }^{\mathrm{d}}$ University Hospital Würzburg, Würzburg, Germany.

Disclosures: Authors have nothing to disclose with regard to commercial support. Received for publication May 29, 2010; revisions received Nov 3, 2010; accepted for publication Jan 20, 2011; available ahead of print March 4, 2011.

Address for reprints: Thomas Metterlein, MD, University Hospital Regensburg, Department of Anesthesiology, Franz-Josef-Strauss-Allee 11, 93051 Regensburg, Germany (E-mail: tom.metterlein@gmx.net).

$0022-5223 / \$ 36.00$

Copyright (c) 2011 by The American Association for Thoracic Surgery doi:10.1016/j.jtcvs.2011.01.034
MH primarily affects the calcium homeostasis of skeletal muscles. Contact with trigger substances leads to a massive calcium release from the sarcoplasmic reticulum in response to a defective ryanodine receptor. ${ }^{1}$ Increased intracellular calcium levels activate contractile filaments and stimulate the cellular energy turnover. Dramatic increases in oxygen consumption and carbon dioxide production are followed by hugely increased production of lactic acid. ${ }^{11}$ The ongoing stimulation finally leads to a breakdown of the cellular metabolism and integrity, and a massive release of muscle enzymes occurs. Without adequate therapy, multiorgan failure develops within hours of onset. Dantrolene blocks the calcium release from the sarcoplasmic reticulum and allows treatment. ${ }^{12,13}$

Classic early symptoms of MH episodes include hemodynamic changes to meet the increased oxygen demand. The expiratory and venous $\mathrm{PCO}_{2}$ values increase, as a result of a dramatic rise in carbon dioxide production. Lactic acidosis, the eponymous hyperthermia, and a generalized rigor develop. ${ }^{2}$ During CPB, these symptoms are often obscured, in part because the MH typical increase of cellular metabolism may be mitigated by the imposed hypothermia. In $\mathrm{MH}$-susceptible pigs, temperatures lower than $35^{\circ} \mathrm{C}$ were able to prevent $\mathrm{MH}$ episodes completely after exposure to 


\section{Abbreviations and Acronyms}

$\mathrm{CPB}=$ cardiopulmonary bypass

$\mathrm{MH}=$ malignant hyperthermia

halothane and succinylcholine. After systemic rewarming, the same substances induced a fulminant $\mathrm{MH}$ crisis in the same animals. ${ }^{14}$ Because of this effect, hypothermia was even discussed as a treatment option before dantrolene was available. ${ }^{15}$

Patients undergoing cardiac surgery often have more significant underlying medical conditions than do other surgical patients. Perioperative complications are therefore attributed to these underlying problems, and a MH diagnosis is thus often delayed or neglected. Timely treatment is essential, so early symptoms must be identified and interpreted appropriately.

Heat and exceptional stress can trigger $\mathrm{MH}$ episodes in susceptible individuals. ${ }^{16}$ Even if classic trigger substances are avoided, rapid rewarming and administration of catecholamine might be able to trigger a MH episode. It is therefore vital to apply appropriate prophylaxis in patients with suspected MH susceptibility.

The aim of this systematic review was to identify potential further cotriggers and early clinical symptoms during CPB that should prompt further attention. Furthermore, applied treatment and prophylactic measures are reviewed and commented on. The purpose is to describe and assess best practice for adequate management of $\mathrm{MH}$-susceptible cardiac surgical patients during $\mathrm{CPB}$.

\section{MATERIALS AND METHODS}

Studies focusing on MH and CPB were systematically searched with MEDLINE, EMBASE, and the Cochrane Library by 2 authors independently (T.M. and P.K.). Any type of report that described CPB in MHsusceptible individuals or a case of $\mathrm{MH}$ in a patient undergoing CPB was to be included, without language restriction. The free text key words were malignant hyperthermia or malignant hyperpyrexia or dantrolene and cardiopulmonary bypass or extracorporeal circulation or cardiac surgery. These were applied in conjunction with the appropriate MeSH terms (malignant hyperthermia and cardiopulmonary bypass or extracorporeal circulation).

Titles were evaluated for relevance and further examined if they were in accordance with the inclusion criteria. In addition, references within the identified studies were hand searched until no further new trials were identified. The last electronic search was performed in June 2010. All relevant articles were retrieved as full-text articles and analyzed in detail.

Data extraction and scoring for validity were performed with established procedures. ${ }^{17}$ Quantitative analysis, or vote counting, was not feasible because of the lack of appropriate data. All retrieved reports were tabulated in a spreadsheet and analyzed in a qualitative manner.

\section{RESULTS}

The systematic search yielded 160 potentially relevant articles. Of these articles, 136 did not deal with the investi- gated topic and therefore were not further analyzed. Overall, 24 reports met the inclusion criteria and were included in the analysis (Table 1). ${ }^{18-41}$

No controlled clinical trial or epidemiologic study dealing with the topic could be found. There were 24 case reports and case series.

Unfortunately, not all case reports gave a detailed description of underlying medical conditions. Preexisting neuromuscular symptoms were described in only 1 patient. A history of cardiomyopathy was documented in only the 2 transplant recipients.

\section{Symptoms of MH Episodes}

Twelve reports described the development of an episode of MH in 14 patients (Table 2). In 3 cases, the first symptoms occurred during $\mathrm{CPB}$; in the remaining 11 cases, shortly after CPB. None of the patients had MH typical symptoms in the prebypass period.

An unexplained increase of the arterial $\mathrm{PCO}_{2}$ was the first symptom in 11 of the 14 cases. During bypass, only 3 patients had an elevated arterial $\mathrm{PCO}_{2}$. Within minutes after rewarming, however, this symptom was present in all patients. Despite dramatically increased minute ventilation (up to $40 \mathrm{~L} / \mathrm{min}$ ), values between $44 \mathrm{~mm} \mathrm{Hg}$ and $67 \mathrm{~mm} \mathrm{Hg}$ were documented. Metabolic acidosis was observed during CPB in only 2 cases. In 6 more cases, metabolic acidosis developed later ( $\mathrm{pH}$ between 7.1 and 7.2). Interestingly, hemodynamic instability was considered a symptom of $\mathrm{MH}$ in only 5 patients. Improvement of the hemodynamic situation, however, was used in 3 of these 5 cases to monitor the treatment success with dantrolene. A rapid recovery of the patient's situation after administration of dantrolene was considered confirmation of an episode of MH. Rigor, another classic clinical sign, was observed in only 2 patients after CPB. In only 3 of the 14 patients with a marked increase in the body temperature was this interpreted as a sign of an episode of MH. In none of the described cases was hyperthermia mentioned as the first symptom.

The massive increase of muscle enzymes, resembling rhabdomolysis, occurred in only 7 of the 14 cases. Creatine kinase levels ranged from 5000 to 38,000 U/L. Early appropriate treatment presumably prevented the development of rhabdomyolysis in the remaining 7 cases.

In 5 of the analyzed cases, a definite MH diagnosis could be made with in vitro contracture testing. In the remaining 7 cases, the clinical course and the adequate response to dantrolene were considered very strong indicators for an episode of MH.

\section{Treatment of MH Episodes}

In a total of 14 cases the treatment was described in detail (Table 3). The administration of trigger substances (if any were used) was immediately discontinued in all cases. 
TABLE 1. List of relevant reports

\begin{tabular}{|c|c|c|c|c|c|c|}
\hline Author(s) & Year & Type & Topic & Age (y) & Surgery & Journal citation \\
\hline Byrick RJ, et al ${ }^{18}$ & 1982 & Case report & Prophylaxis & 54 & CABG & Can Anaesth Soc J. 1982;29:50-4 \\
\hline MacGillivray RG, et al ${ }^{19}$ & 1986 & Case report & MH crisis & 2 & $\begin{array}{l}\text { Tetralogy of } \\
\text { Fallot correction }\end{array}$ & Can Anaesth Soc J. 1986;33:509-14 \\
\hline Larach DR, et $\mathrm{al}^{20}$ & 1987 & Case report & Prophylaxis & 2 & VSD correction & $\begin{array}{l}\text { J Cardiothorac Anesth. } \\
\text { 1987;1:448-53 }\end{array}$ \\
\hline Landymore RW, et $\mathrm{al}^{21}$ & 1987 & Case report & MH crisis & 54 & CABG & Can J Surg. 1987;30:209-11 \\
\hline Richardson $\mathrm{J}^{22}$ & 1987 & Case report & Prophylaxis & 46 & CABG & Anaesthesia. 1987;42:1125 \\
\hline Marks LF, et a ${ }^{23}$ & 1988 & Case report & Prophylaxis & 87 & CABG & $\begin{array}{l}\text { Anaesth Intensive Care. } \\
\text { 1988;16:482-5 }\end{array}$ \\
\hline Kleinman $\mathrm{B}$, et $\mathrm{al}^{24}$ & 1990 & Case series & MH crisis & $57 ; 65$ & $\begin{array}{l}\text { CABG; aortic-valve } \\
\text { plus CABG }\end{array}$ & $\begin{array}{c}\text { Cardiothorac Anesth. } \\
\text { 1990;4:385-99 }\end{array}$ \\
\hline Comunale ME, et a ${ }^{25}$ & 1991 & Case report & Prophylaxis & 56 & CABG & $\begin{array}{l}\text { J Cardiothorac Vasc Anesth. } \\
\text { 1991;5:153-5 }\end{array}$ \\
\hline Mongan PD, et $\mathrm{al}^{26}$ & 1992 & Case report & Prophylaxis & 3 & ASD correction & Can J Anaesth. 1992;39:99-100 \\
\hline Hachenberg $\mathrm{T}$, et $\mathrm{al}^{27}$ & 1992 & Case report & Prophylaxis & 27 & Transplant & $\begin{array}{l}\text { J Cardiothorac Vasc Anesth. } \\
\text { 1992;6:386-7 }\end{array}$ \\
\hline Quinn $\mathrm{RD}$, et $\mathrm{al}^{28}$ & 1992 & Case report & MH crisis & 41 & Mitral valve & Ann Thorac Surg. 1992;53:1114-6 \\
\hline Koehntop DE, et $\mathrm{al}^{29}$ & 1997 & Case report & Prophylaxis & 14 & Transplant & Anesth Analg. 1997;85:229-30 \\
\hline Abe $\mathrm{K}$, et $\mathrm{al}^{30}$ & 1997 & Case series & MH crisis & $64 ; 69$ & $\begin{array}{l}\text { CABG; } \\
\text { mitral valve }\end{array}$ & Can J Anaesth. 1997;44:662-5 \\
\hline Allen $\mathrm{GC}$, et $\mathrm{al}^{31}$ & 1998 & Case report & $\begin{array}{l}\text { MH crisis } \\
\text { with prophylaxis }\end{array}$ & 55 & CABG & Can J Anaesth. 1989;36:81-5 \\
\hline Lindholm $\mathrm{P}$, et $\mathrm{al}^{32}$ & 2000 & Case report & $\mathrm{MH}$ crisis & 77 & $\begin{array}{l}\text { Aortic valve } \\
\text { plus CABG }\end{array}$ & $\begin{array}{l}\text { J Cardiothorac Vasc Anesth. } \\
\text { 2000;14:576-8 }\end{array}$ \\
\hline Riess FC, et al ${ }^{33}$ & 2001 & Case report & MH crisis & 48 & Aortic valve & Anesthesiology. 2001;94:355-7 \\
\hline Johi RR, et $\mathrm{al}^{34}$ & 2003 & Case report & Prophylaxis & 44 & CABG & Br J Anaesth. 2003;91:744-7 \\
\hline Girard $\mathrm{T}$, et $\mathrm{al}^{35}$ & 2003 & Case report & Prophylaxis & 55 & CABG & $\begin{array}{l}\text { Acta Anaesthesiol Scand. } \\
\text { 2003;47:233-5 }\end{array}$ \\
\hline Pandya $\mathrm{AB}$, et al ${ }^{36}$ & 2003 & Case report & MH crisis & 42 & Mitral valve & $\begin{array}{l}\text { J Cardiothorac Vasc Anesth. } \\
\text { 2003; } 17: 625-8\end{array}$ \\
\hline Jonassen $\mathrm{AA}$, et $\mathrm{al}^{37}$ & 2004 & Case report & MH crisis & 56 & $\begin{array}{l}\text { Mitral valve } \\
\text { plus CABG }\end{array}$ & $\begin{array}{l}\text { Acta Anaesthesiol Scand. } \\
\text { 2004;48:1062-5 }\end{array}$ \\
\hline Lichtman $\mathrm{AD}$, et $\mathrm{al}^{38}$ & 2006 & Case report & $\begin{array}{l}\text { MH crisis } \\
\text { with prophylaxis }\end{array}$ & 54 & CABG & Anesth Analg. 2006;102:372-5 \\
\hline Siddik-Sayyid SM, et al ${ }^{39}$ & 2007 & Case report & Prophylaxis & 75 & CABG & $\begin{array}{l}\text { Anesth Analg. 2007;104:214; } \\
\text { author reply, 214-5 }\end{array}$ \\
\hline Aeschlimann $\mathrm{N}$, et $\mathrm{al}^{40}$ & 2009 & Case report & Prophylaxis & 58 & CABG & $\begin{array}{l}\text { J Cardiothorac Vasc Anesth. } \\
\text { 2009;23:134-5 }\end{array}$ \\
\hline Firstenberg M, et $\mathrm{al}^{41}$ & 2010 & Case report & MH crisis & 69 & CABG & Ann Thorac Surg. 2010;89:947-8 \\
\hline
\end{tabular}

$C A B G$, Coronary artery bypass grafting; $M H$, malignant hyperthermia; $V S D$, ventricular septal defect; $A S D$, atrial septal defect.

Furthermore, dantrolene was administered in all but 1 case. That patient died after development of acute renal failure caused by massive rhabdomyolysis. All other patients received dantrolene, with dosages ranging from 1.0 to $11.0 \mathrm{mg} / \mathrm{kg}$, and survived the MH episode. The patient who received a total of $11 \mathrm{mg} / \mathrm{kg}$ dantrolene had development of a profound muscular weakness that prevented early extubation. The further clinical course was then complicated by pneumonia in conjunction with prolonged ventilation. In all other cases, no dantrolene-related side effects were observed. None of the reports mentioned any negative inotropic effects of dantrolene. To monitor the success of the causal therapy with dantrolene, both improvement of the hemodynamic instability ( 3 cases), and decrease of the measured arterial $\mathrm{PCO}_{2}$ ( 8 cases) were used.

Additional supportive care was given and included fluid administration and vasopressors for refractory hypotension. Low cardiac output was treated with inotropic agents and mechanical assist devices, such as intra-aortic balloon pump support. No complications related to the use of catecholamines or inotropic agents were observed in these individuals. Various antiarrhythmic drugs, including digoxin, lidocaine, and propranolol, were used to treat arrhythmias.

Among the 7 patients with rhabdomyolysis, only 4 developed acute renal failure and had to be treated with hemodialysis. One of these 4 patients died (the patient without 
TABLE 2. Symptoms that occurred during or shortly after cardiopulmonary bypass, as described in 14 published malignant hyperthermia episodes

\begin{tabular}{lc}
\hline \multicolumn{1}{c}{ Symptom } & No. of cases \\
\hline Total & 14 \\
Unexplained increase in arterial $\mathrm{PCO}_{2}$ & 14 \\
Metabolic acidosis & 9 \\
Unexplained hemodynamic instability & 5 \\
Rigor & 2 \\
Increased serum creatine kinase & 7 \\
$\quad$ and myoglobin levels & \\
\hline
\end{tabular}

dantrolene treatment); all others regained sufficient renal function.

\section{Potential Trigger Substances}

In 10 of the 14 described cases, volatile anesthetics as classic trigger substances were identified (Table 4). In one of these cases, succinylcholine was used for emergency reintubation in the intensive care unit. This patient had an abortive MH episode develop after administration of enflurane and a fulminant $\mathrm{MH}$ crisis after treatment with succinylcholine. In 4 cases no classic trigger agents were used. Rapid and exaggerated rewarming was considered to be the trigger in 2 of these 4 cases. In 1 case report, enoximone, a phosphodiesterase III inhibitor, was implicated as trigger. In that case report, however, no data on the rewarming process was presented. In 1 additional case, no trigger could be identified at all. Again, no information on the rewarming process was presented.

\section{Prevention of MH Episodes in Known Susceptible Patients During CPB}

A total of 14 reports of cases described measures to prevent an episode of MH in patients known $(\mathrm{n}=10)$ or suspected $(\mathrm{n}=4)$ to be MH susceptible (Table 5). In 12 cases an $\mathrm{MH}$ episode was prevented, whereas 2 still had MH crises develop.

Trigger agents were avoided in all cases, and only decontaminated anesthesia machines and oxygenators were used. Anesthesia was induced and maintained with opiates and intravenous hypnotics. Relaxation was achieved with nondepolarizing neuromuscular-blocking agents. Dantrolene

TABLE 3. Treatment of malignant hyperthermia crisis as described in 14 published case reports

\begin{tabular}{lc}
\hline \multicolumn{1}{c}{ Treatment } & No. of cases \\
\hline Total & 14 \\
Discontinuation of trigger substances & 11 \\
Administration of dantrolene & 13 \\
Hemodynamic stabilization with volume & 11 \\
$\quad$ administration, vasopressors, and inotropic agents & \\
Antiarrhythmic agents & 4 \\
\hline
\end{tabular}

TABLE 4. Potential triggers of the MH malignant hyperthermia episodes in 14 published cases

\begin{tabular}{lc}
\hline \multicolumn{1}{c}{ Trigger } & No. of cases \\
\hline Total & 14 \\
Volatile anesthetics (halothane, & 10 \\
$\quad$ enflurane, isoflurane, sevoflurane) & 1 \\
Succinylcholine & 2 \\
Rapid and exaggerated rewarming alone & 2 \\
Unknown (possibly enoximone or rewarming) & \\
\hline Sums to 15 because 1 patient received both enflurane and succinylcholine.
\end{tabular}

prophylaxis was applied in 5 cases, with dosages ranging from $2.0 \mathrm{mg} / \mathrm{kg}$ to $6.0 \mathrm{mg} / \mathrm{kg}$. None of the patients who received dantrolene showed signs of hypermetabolism. Two of the 9 patients with suspected MH susceptibility who had no dantrolene prophylaxis had MH crises develop. In these 2 cases, no definite trigger could be identified. In both cases, however, no attention was paid to the rewarming process. A heat-induced $\mathrm{MH}$ episode therefore could not be excluded. Because of the potential danger, rewarming was done slowly and stopped at $36^{\circ} \mathrm{C}$ in 3 of the 14 patients. The aim was to maintain a core temperature under $36^{\circ} \mathrm{C}$ in the postoperative period. No $\mathrm{MH}$ episodes were described in any of these cases, even without dantrolene prophylaxis.

One case report even noted avoidance of inotropic agents. Hypotension and low output were instead treated with volume substitution and an intra-aortic balloon pump. In all other cases, inotropic agents were used without reported problems.

Overall, 17 patients received dantrolene in the perioperative period. A significant muscular weakness developed in 4 of these patients. Direct negative inotropic effects of dantrolene were not observed.

\section{DISCUSSION}

The current systematic review provides evidence that the nature of $\mathrm{MH}$ episodes observed during $\mathrm{CPB}$ does not markedly differ from other MH episodes. The heterogeneous picture of symptoms present as first signs, however, highlights the hypothesis that the CPB setting makes an early diagnosis and timely treatment more difficult than in other settings. MH is a potentially lethal disease. The reported outcomes in

TABLE 5. Preventive measures in cases of a known or suspected MH malignant hyperthermia susceptibility, as described in 14 published cases

\begin{tabular}{lc}
\hline \multicolumn{1}{c}{ Preventive measures } & No. of cases \\
\hline Total & 14 \\
Avoid contact with trigger substances & 14 \\
Slow and careful rewarming & 3 \\
Dantrolene & 5 \\
Avoid inotropic agents & 1 \\
\hline
\end{tabular}


the reviewed cases (only 1 patient died) cannot be viewed as indicating a less severe characteristic of $\mathrm{MH}$ during CPB. Cases with negative outcome may not have been published, thus creating a significant reporting bias.

\section{Detection of MH by Classic Symptoms}

All described cases document that classic MH symptoms are obscured and can be misinterpreted. It therefore must be suspected that an episode of MH could even be missed in some cases because symptoms typical of $\mathrm{MH}$ are attributed to other factors involved in cardiac surgery.

The earliest symptom was an unexplained increase in the arterial $\mathrm{PCO}_{2}$. Because of a massive increase of the cellular metabolism in $\mathrm{MH}$, enormous amounts of carbon dioxide are produced. ${ }^{1}$ Even an adaptation of the minute ventilation is often not sufficient to achieve normal values. During $\mathrm{CPB}$, expiratory $\mathrm{PCO}_{2}$ is not measured. Therefore detection of this early sensitive sign can be delayed unless frequent monitoring of the arterial $\mathrm{PCO}_{2}$ takes place and is correlated with the applied (increased) sweep gas flow.

After depletion of the oxidative reserve, lactic acid is produced in the muscle. An increase in arterial serum lactate is seen early during MH crisis, because the metabolic capacity of the liver is reduced during an episode of $\mathrm{MH}^{2,42}$ During cardiac surgery, periods of impaired tissue oxygenation may occur, with subsequent development of lactic acidosis. Point of care measurements for lactic acid would allow a timely detection of a developing mismatch in oxygenation. A profound drop in the mixed venous saturation would be another indication of the massive increase in tissue oxygen demand. ${ }^{43}$

Hemodynamic instability is a further classic symptom of an episode of $\mathrm{MH}$. $^{1}$ During and right after CPB, however, patients often undergo periods of arrhythmias and hypotension. Therefore the hemodynamic situation is not necessarily conducive to diagnosis of $\mathrm{MH}$ crisis.

After administration of dantrolene, the hemodynamic situation usually rapidly improves in MH episodes. This response can be used to confirm the working diagnosis and to monitor the success of the treatment. ${ }^{4,44}$ Because other causes may contribute to hemodynamic instability, however, clinicians may not be able to determine the necessary amount of dantrolene to administer without a change in the hemodynamic instability.

Rigor, another classic clinical sign of $\mathrm{MH}$, is often missing during cardiac surgery. This may be because some patients receive high amounts of nondepolarizing neuromuscular-blocking agents. The profound paralysis induced by these agents attenuates the induced rigor without preventing development of $\mathrm{MH}^{45}$

For obvious reasons, the eponymous hyperthermia can only develop after termination of CPB with temperature control. Inhomogeneous and rapid rewarming can sometimes lead to core body temperatures above $38^{\circ} \mathrm{C}$, and may therefore be ignored as a symptom of MH. Hyperthermia was not the first symptom in any of the described cases. In fact, in general, hyperthermia is a rather late symptom in an episode of MH. Metabolic changes, in cardiac patients as well as in other patient populations, occur earlier and are more sensitive. ${ }^{11}$

Another late sign of an episode of $\mathrm{MH}$ is the development of rhabdomyolysis. ${ }^{1}$ Variable increases of creatine kinase and myoglobin levels are often seen in surgical patients; however, above average increases in muscle enzymes must lead to suspicion of MH. The usefulness of rhabdomyolysis as a sign for $\mathrm{MH}$ is further impaired by the fact that various test assays cannot distinguish between myoglobin and hemoglobin. Thus in the postcardiosurgical setting, a positive test result might be misinterpreted as indicating hemolysis related to CPB.

In the analyzed cases, $\mathrm{MH}$ symptoms occurred either during or shortly after CPB. An adequate diagnosis may be complicated by the delayed onset of MH symptoms. The initial presentation may even begin in the postoperative period. A recent study, however, revealed that so-called "postoperative MH" is very uncommon ( $<2 \%$ of all cases) and usually occurs within less than an hour after discontinuation of the trigger. ${ }^{46}$

\section{Treatment of Supposed MH Episodes}

As a first step in managing a potential $\mathrm{MH}$ episode, the administration of any trigger substances used must be discontinued immediately. Anesthesia must be maintained with intravenous anesthetics and nondepolarizing neuromuscular-blocking agents.

The only treatment option is dantrolene, which blocks the calcium release from the sarcoplasmic reticulum by interfering with the activated type 1 ryanodine receptor. Early treatment of an episode of $\mathrm{MH}$ can decrease the mortality from greater than $80 \%$ to less than $5 \%{ }^{2,42}$ Current guidelines recommend the administration of $2.5 \mathrm{mg} / \mathrm{kg}$ every 5 minutes, until a clinical improvement is seen., ${ }^{2,7}$ Previous studies were able to show that no dosing adjustments have to be made during $\mathrm{CPB}$, because only the initiation of the CPB leads to a slight decrease in blood levels, as a result of dilution. ${ }^{47}$ After administration of $10 \mathrm{mg} / \mathrm{kg}$, without clinical improvement, a differential diagnosis has to be considered. ${ }^{2,47}$

Dantrolene can induce a profound muscular weakness by interfering with the intracellular calcium handling. ${ }^{11}$ This side effect should not prevent sufficient treatment, but it must be considered. Negative inotropic effects were not described in the reviewed case reports. In previous animal studies, however, higher than recommended doses induced negative inotropic effects. ${ }^{48,49}$

To improve the hemodynamic situation, supportive care should be given. Refractory hypotension is treated with volume administration and vasopressors. Low cardiac output can be treated with inotropic agents and mechanical assist 
devices, such as intra-aortic balloon pump support. No complications related to the use of inotropic agents have been documented in MHS-susceptible individuals. Various antiarrhythmic drugs can be used to treat arrhythmias. The current guidelines advise the use of $\beta$-blockers, as described in the newer case reports. ${ }^{44}$ Before the acute situation is under control, separation from CPB should not be recommended, because both hemodynamics and temperature can easily be manipulated.

Cardiac surgical patients, in general, have an increased risk of development of acute renal injury. Additionally, almost all untreated $\mathrm{MH}$ episodes result in rhabdomyolysis, with the risk of direct myoglobin-mediated damage to the kidney. ${ }^{1}$ An adequate therapy to prevent kidney damage includes aggressive fluid replacement with crystalloids. Diuretics should be used to maintain an adequate urinary flow. This decreases the risk of myoglobin precipitation and flushes nephrotoxic agents through the tubules. Whether osmodiuretics lead to a better outcome than loop diuretics is unknown. Whether alkalization has a significant benefit is also not certain. Nephroprotective effects of antioxidants or vitamins could not be demonstrated in larger trials. ${ }^{50}$ Preventive hemofiltration or hemodialysis does not show a benefit. Renal replacement therapy should therefore be initiated according to the clinical routine., ${ }^{2,50}$

\section{Potential Trigger Agents of MH}

All volatile anesthetics and also succinylcholine are considered classic trigger substances for MH. ${ }^{1,3}$ Further potential triggers have been discussed in the literature. Gasoline vapors and serotonin receptor agonists are considered potential trigger agents. ${ }^{51,52}$ The role of the body core temperature in human $\mathrm{MH}$ remains controversial. In $\mathrm{MH}-$ susceptible pigs, episodes can be induced by heat alone. ${ }^{11}$ Physical activity in a hot, humid environment can trigger $\mathrm{MH}$ in human beings. ${ }^{53}$ Patients with a preexisting fever are at a higher risk of development of an episode of MH. Whether heat itself is capable of triggering $\mathrm{MH}$ in human beings is not known, but the possibility cannot be excluded, and at least a modulating effect on a developing crisis must be assumed. ${ }^{1}$ During rapid and exaggerated rewarming, body core temperatures above physiologic levels can be reached.

Inotropic agents increase the intracellular calcium level and are therefore at least theoretically capable of triggering an episode of MH. In animal studies, however, even extremely high concentrations of enoximone were not capable of triggering a hypermetabolic reaction. ${ }^{54}$ A modulating effect of inotropes on a developing $\mathrm{MH}$ reaction, however, cannot be excluded. The calcium sensitizer levosimendan does not increase the intracellular calcium level, ${ }^{55}$ so any influence on cellular calcium handling in $\mathrm{MH}$-susceptible individuals seems unlikely.

Theoretically, a further trigger is possible, as 4-chloro-mcresol, a preservative contained in heparin, can induce in vitro a reaction similar to $\mathrm{MH}{ }^{43,56}$ In $\mathrm{MH}$-susceptible swine, however, only doses 150 -fold higher than those contained in preparations used clinically were able to induce a reaction in vivo. It therefore seems unlikely that this agent contributes to the occurrence of $\mathrm{MH}$ in human beings. ${ }^{43,57}$

\section{Prevention of MH Episodes in MH-Susceptible Patients}

Basic preventive measures include the avoidance of trigger substances. The vapor has to be removed, and the tubing and the carbon dioxide absorber must be renewed. According to various guidelines, the anesthesia machines should be decontaminated with a high flow of pure oxygen for at least 10 minutes. ${ }^{44}$ The same measures must be applied to the oxygenator of the $\mathrm{CPB}$ circuit.

For induction and maintenance of general anesthesia, opiates and intravenous hypnotics can be used without problems. Nondepolarizing neuromuscular-blocking agents are also considered safe. ${ }^{11}$

Controversially, preoperative dantrolene prophylaxis has been discussed; however, MH episodes still occur with dantrolene prophylaxis. ${ }^{58}$ Additionally, early signs of $\mathrm{MH}$ crisis may be obscured, delaying subsequent treatment. These limiting factors have to be evaluated critically in light of the potential side effects of dantrolene. ${ }^{59}$ Namely, a considerable number of patients treated with dantrolene, especially those with preexisting neuromuscular disorders, have relevant muscular weakness develop. ${ }^{60}$ In our view, in the 2 cases in which MH episodes occurred despite suspected susceptibility, it is possible that a MH episode could have been prevented with more attention to the rewarming process, even without dantrolene prophylaxis. Newer guidelines no longer recommend the prophylactic administration of dantrolene. Appropriate monitoring allows the early detection of symptoms, and consequent treatment prevents negative outcomes. ${ }^{44}$

Special attention has to be paid to the rewarming process because of its potential influence on the body core temperature. Rewarming should be done slowly and stopped at $36^{\circ} \mathrm{C}$. The aim is to maintain a core temperature of less than $36^{\circ} \mathrm{C}$ during the postoperative period in $\mathrm{MH}-$ susceptible patients; however, the effects of this mild hypothermia on coagulation must be considered.

Both catecholamines and phosphodiesterase III inhibitors are considered safe drugs. The placement of a complication-prone mechanical assist device simply to avoid inotropic agents seems not to be justified by the available data.

\section{CONCLUSIONS}

With the frequent use of volatile anesthetics, $\mathrm{MH}$ will remain a topic in cardiac anesthesia. Classic symptoms of an episode of $\mathrm{MH}$ are often obscured during $\mathrm{CPB}$. $\mathrm{MH}$ as a differential diagnosis, however, has to be considered with the 
occurrence of various otherwise inexplicable symptoms. Rapid rewarming could play an important role in the development of MH episodes and thus may prove a relevant cofactor in the surgical setting if CPB is applied. Treatment with dantrolene, the only curative approach, must not be delayed. The development of MH episodes in susceptible individuals, can be avoided with simple interventions. Anesthesiologists, perfusionists, and cardiac surgeons must be familiar with these measures, and warning signs should be added to respective checklists to facilitate early detection and treatment.

We are grateful to Miss Elise Palmer and Mrs Mantel for proofreading the manuscript.

\section{References}

1. Rosenberg H, Davis M, James D, Pollock N, Stowell K. Malignant hyperthermia. Orphanet J Rare Dis. 2007;2:21.

2. Steinfath M, Wappler F, Scholz J. [Malignant hyperthermia. General, clinical and experimental aspects]. Anaesthesist. 2002;51:328-45. quiz 346-7. German.

3. Wappler F, Fiege M. Is desflurane a "weak" trigger of malignant hyperthermia? Anesth Analg. 2003;97:295.

4. Hopkins PM. Malignant hyperthermia: advances in clinical management and diagnosis. Br J Anaesth. 2000;85:118-28. Erratum in: Br J Anaesth. 2001;86:605.

5. Denborough MA, Forster JF, Lovell RR, Maplestone PA, Villiers JD. Anaesthetic deaths in a family. Br J Anaesth. 1962;34:395-6.

6. Hartung E, Anetseder M, Olthoff D, Deutrich C, Lehmann-Horn F, Baur C, et al. [Regional distribution of predisposition to malignant hyperthermia in Germany: rate in 1997]. Anasthesiol Intensivmed Notfallmed Schmerzther. 1998;33: 238243. German.

7. Brady JE, Sun LS, Rosenberg H, Li G. Prevalence of malignant hyperthermia due to anesthesia in New York State, 2001-2005. Anesth Analg. 2009;109:1162-6.

8. Ball SP, Johnson KJ. The genetics of malignant hyperthermia. J Med Genet. 1993;30:89-93.

9. Larach MG, Localio AR, Allen GC, Denborough MA, Ellis FR, Gronert GA, et al. A clinical grading scale to predict malignant hyperthermia susceptibility. Anesthesiology. 1994;80:771-9.

10. Monnier N, Krivosic-Horber R, Payen JF, Kozak-Ribbens G, Nivoche Y, Adnet P, et al. Presence of two different genetic traits in malignant hyperthermia families: implication for genetic analysis, diagnosis, and incidence of malignant hyperthermia susceptibility. Anesthesiology. 2002;97:1067-74.

11. Wappler F. Malignant hyperthermia. Eur J Anaesthesiol. 2001;18:632-52.

12. Roewer N. [Malignant hyperthermia today]. Anasthesiol Intensivmed Notfallmed Schmerzther. 1991;26:431-49. German.

13. Gerbershagen MU, Fiege M, Krause T, Agarwal K, Wappler F. [Dantrolene. Pharmacological and therapeutic aspects]. Anaesthesist. 2003;52:238-45. German.

14. Iaizzo PA, Kehler CH, Carr RJ, Sessler DI, Belani KG. Prior hypothermia attenuates malignant hyperthermia in susceptible swine. Anesth Analg. 1996;82: 803-9.

15. Ryan JF, Donlon JV, Malt RA, Bland JH, Buckley MJ, Sreter FA, et al. Cardiopulmonary bypass in the treatment of malignant hyperthermia. $N$ Engl J Med. 1974;290:1121-2.

16. Capacchione JF, Muldoon SM. The relationship between exertional heat illness, exertional rhabdomyolysis, and malignant hyperthermia. Anesth Analg. 2009; 109:1065-9.

17. Kranke P. Systematic reviews. Eur J Anaesthesiol. 2010;27:763-72.

18. Byrick RJ, Rose DK, Ranganathan N. Management of a malignant hyperthermia patient during cardiopulmonary bypass. Can Anaesth Soc J. 1982;29:50-4.

19. MacGillivray RG, Jann H, Vanker E, Gemmell L, Mahomedy AE. Development of malignant hyperthermia obscured by cardiopulmonary bypass. Can Anaesth Soc J. 1986;33:509-14.

20. Larach DR, High KM, Larach MG, Hensley FA Jr, Martin DE, Williams DR. Cardiopulmonary bypass interference with dantrolene prophylaxis of malignant hyperthermia. J Cardiothorac Anesth. 1987;1:448-53.

21. Landymore RW, Allen C, Johnstone D, Wood J. Malignant hyperthermia: a dilemma for the cardiac surgeon. Can J Surg. 1987;30:209-11.
22. Richardson J. Propofol infusion for coronary artery bypass surgery in a patient with suspected malignant hyperpyrexia. Anaesthesia. 1987;42:1125.

23. Marks LF, Edwards JC, Linter SP. Propofol during cardiopulmonary bypass in a patient susceptible to malignant hyperpyrexia. Anaesth Intensive Care. 1988; $16: 482-5$.

24. Kleinman B, Kalathiveetil J, Jain U, Blakeman B, Glisson S, D'Ambra MN, et al. Case conference 3-1990. Two patients develop some signs and symptoms of malignant hyperthermia during cardiac surgery with cardiopulmonary bypass-is it the real thing? J Cardiothorac Anesth. 1990;4:385-99.

25. Comunale ME, DiNardo JA, Schwartz MJ. Pharmacokinetics of dantrolene in an adult patient undergoing cardiopulmonary bypass. J Cardiothorac Vasc Anesth. 1991;5:153-5.

26. Mongan PD, Hosking MP. Hyperthermia after cardiopulmonary bypass in a child. Can J Anaesth. 1992;39:99-100.

27. Hachenberg T, Brussel T, Lawin P, Konertz W, Scheld HH. Heart transplantation in a patient with central core disease. J Cardiothorac Vasc Anesth. 1992;6: 386-7.

28. Quinn RD, Pae WE Jr, McGary SA, Wickey GS. Development of malignant hyperthermia during mitral valve replacement. Ann Thorac Surg. 1992;53: 1114-6.

29. Koehntop DE, Beebe DS, Belani KG. The safety of dantrolene in a patient with a severe cardiomyopathy requiring a heart transplant. Anesth Analg. 1997;85:229-30.

30. Abe K, Miyamoto Y, Ohnishi K. Hyperthermia after cardiac surgery. Can J Anaesth. 1997;44:662-5.

31. Allen GC, Cattran CB. Rewarming following hypothermic cardiopulmonary bypass in the malignant hyperthermia-susceptible patient: implications for diagnosis and perioperative management. Can J Anaesth. 1989;36:81-5.

32. Lindholm P, Andersen S, Andersen C, Fisker J. Development of malignant hyperthermia during cardiopulmonary bypass. J Cardiothorac Vasc Anesth. 2000;14: 576-8.

33. Riess FC, Fiege M, Moshar S, Bergmann H, Bleese N, Kormann J, et al. Rhabdomyolysis following cardiopulmonary bypass and treatment with enoximone in a patient susceptible to malignant hyperthermia. Anesthesiology. 2001;94: 355-7.

34. Johi RR, Mills R, Halsall PJ, Hopkins PM. Anaesthetic management of coronary artery bypass grafting in a patient with central core disease and susceptibility to malignant hyperthermia on statin therapy. Br J Anaesth. 2003;91:744-7.

35. Girard T, Bally S, Langer I, Schurch M. Diagnosis of malignant hyperthermia susceptibility during CABG surgery. Acta Anaesthesiol Scand. 2003;47: 233-5.

36. Pandya AB, O'Leary CE. Development of malignant hyperthermia post-cardiopulmonary bypass during surgery for mitral valve replacement. J Cardiothorac Vasc Anesth. 2003; 17:625-8.

37. Jonassen AA, Petersen AJ, Mohr S, Andersson C, Skattum J, Kvernebo K, et al. Sevoflurane-induced malignant hyperthermia during cardiopulmonary bypass and moderate hypothermia. Acta Anaesthesiol Scand. 2004;48:1062-5.

38. Lichtman AD, Oribabor C. Malignant hyperthermia following systemic rewarming after hypothermic cardiopulmonary bypass. Anesth Analg. 2006; 102:372-5.

39. Siddik-Sayyid SM, Moussa AR, Baraka AS. Can we prevent malignant hyperthermia after hypothermic cardiopulmonary bypass in a malignant hyperthermia-susceptible patient? Anesth Analg. 2007;104:214-5.

40. Aeschlimann N, Merino W, Lema G. Malignant hyperthermia and cardiac surgery. J Cardiothorac Vasc Anesth. 2009;23:134-5.

41. Firstenberg M, Abel E, Blais D, Andritsos M. Delayed malignant hyperthermia after routine coronary artery bypass. Ann Thorac Surg. 2010;89:947-8.

42. Adnet PJ, Gronert GA. Malignant hyperthermia: advances in diagnostics and management. Curr Opin Anaesthesiol. 1999;12:353-8.

43. Wappler F, Scholz J, Fiege M, Kolodzie K, Kudlik C, Weisshorn R, et al. 4-chloro-m-cresol is a trigger of malignant hyperthermia in susceptible swine. Anesthesiology. 1999;90:1733-40.

44. DGAInfo Empfehlung zur Therapie der malignen Hyperthermie. Anästh Intensivmed. 2008;9:483-8.

45. Iaizzo PA, Wedel DJ. Response to succinylcholine in porcine malignant hyperthermia. Anesth Analg. 1994;79:143-51.

46. Litman RS, Flood CD, Kaplan RF, Kim YL, Tobin JR. Postoperative malignant hyperthermia: an analysis of cases from the North American Malignant Hyperthermia Registry. Anesthesiology. 2008;109:825-9.

47. Comunale ME, DiNardo JA, Schwartz MJ. Pharmacokinetics of dantrolene in an adult patient undergoing cardiopulmonary bypass. J Cardiothorac Vasc Anesth. 1991;5:153-5. 
48. Saltzman LS, Kates RA, Corke BC, Norfleet EA, Heath KR. Hyperkalemia and cardiovascular collapse after verapamil and dantrolene administration in swine. Anesth Analg. 1984;63:473-8.

49. Meyler MJ, Wesseling H, Agoston S. The effects of dantrolene sodium on cardiac and skeletal muscle in rats. Eur J Pharmacol. 1976;39:127-31.

50. Bosch X, Poch E, Grau JM. Rhabdomyolysis and acute kidney injury. N Engl J Med. 2009;361:62-72.

51. Wappler F, Roewer N, Köchling A, Scholz J, Steinfath M, Rumberger E, et al. Effects of serotonin 2 receptor agonists on skeletal muscle preparations in patients with a disposition toward malignant hyperthermia [In German]. Anaesthesist. 1995;44:538-44.

52. Anetseder M, Hartung E, Klepper S, Reichmann H. Gasoline vapors induce severe rhabdomyolysis. Neurology. 1994;44:2393-5.

53. Wappler F, Fiege M, Steinfath M, Agarwal K, Scholz J, Singh S, et al. Evidence for susceptibility to malignant hyperthermia in patients with exercise-induced rhabdomyolysis. Anesthesiology. 2001;94:95-100.

54. Fiege M, Wappler F, Weisshorn R, Gerbershagen MU, Kolodzie K, Schulte am EJ. Phosphodiesterase-III-inhibition with amrinone leads to contracture development in skeletal muscle preparations of malignant hyperthermia susceptible swine. Eur J Anaesthesiol. 2005;22:283-8.
55. Buckberg G, Mahajan A, Saleh S, Hoffman JI, Coghlan C. Structure and function relationships of the helical ventricular myocardial band. $J$ Thorac Cardiovasc Surg. 2008;136:578-89. 589.e1-11.

56. Gerbershagen MU, Fiege M, Weisshorn R, Kolodzie K, Schulte am Esch J, Wappler F. Cumulative and bolus in vitro contracture testing with 4-chloro-3-ethylphenol in malignant hyperthermia positive and negative human skeletal muscles. Anesth Analg. 2005;101:710-4. table of contents.

57. Wappler F, Anetseder M, Baur CP, Censier K, Doetsch S, Felleiter P, et al. Multicentre evaluation of in vitro contracture testing with bolus administration of 4-chloro-m-cresol for diagnosis of malignant hyperthermia susceptibility. Eur J Anaesthesiol. 2003;20:528-36.

58. Ruhland G, Hinkle AJ. Malignant hyperthermia after oral and intravenous pretreatment with dantrolene in a patient susceptible to malignant hyperthermia. Anesthesiology. 1984;60:159-60.

59. Michalek-Sauberer A, Gilly H. Prophylactic use of dantrolene in a patient with central core disease. Anesth Analg. 1998;86:915-6.

60. Min JY, Meissner A, Feng X, Wang J, Malek S, Wang JF, et al. Dantrolene: effects on abnormal intracellular $\mathrm{Ca}(2+)$ handling and inotropy in postinfarcted rat myocardium. Eur J Pharmacol. 2003;471:41-7. 